\title{
A Survey on the Perception of Companion Plants for Eco-Friendly Urban Agriculture among Urban Residents
}

\author{
In-Kyoung Hong ${ }^{1}$, Hyung Kwon Yun ${ }^{2 *}$, Young-Bin Jung ${ }^{3}$, and Sang-Mi Lee ${ }^{4}$ \\ ${ }_{1}^{1}$ Postdoctoral researcher, Urban Agricultural Research Division, National Institute of Horticultural and Herbal Science, Rural Development \\ Administration, Wanju-gun, Jeollabuk-do 55365, Korea \\ ${ }^{2}$ Senior researcher, Urban Agricultural Research Division, National Institute of Horticultural and Herbal Science, Rural Development \\ Administration, Wanju-gun, Jeollabuk-do 55365, Korea \\ ${ }^{3}$ Researcher, Urban Agricultural Research Division, National Institute of Horticultural and Herbal Science, Rural Development \\ Administration, Wanju-gun, Jeollabuk-do 55365, Korea \\ ${ }^{4}$ Researcher, Urban Agricultural Research Division, National Institute of Horticultural and Herbal Science, Rural Development \\ Administration, Wanju-gun, Jeollabuk-do 55365, Korea
}

\section{ABSTRACT}

Background and objective: This study was conducted as part of research to promote garden diversity and seek sustainable garden management plans, as well as to determine the trends in understanding and use of companion plants as an eco-friendly farming method and provide the results as the basic data for sustainable urban agriculture.

Methods: To determine the trends in garden activities, eco-friendly pest control, and use of companion plants, a survey was conducted on 230 urban residents participating in the Urban Agriculture Expert course. 223 copies of the questionnaire were collected excluding missing values, and IBM SPSS statistics Ver. 25 Program was used for frequency analysis, descriptive statistics, and regression analysis.

Results: Most of the respondents were female (71.3\%), homemakers (26.5\%), were in their 50s (29.1\%), and had 2 members in the family (27.8\%). 164 respondents (73.5\%) had experience in gardening, most of them once a week (31.7\%) and for self-consumption (55.5\%). Both men and women raised crops for safe food production (32.3\%), and they most preferred the city garden type (39.9\%). For the preparation of nourishment for eco-friendly garden management, most respondents $(60.1 \%)$ purchased fertilizers from the market. For the reason why eco-friendly pest control is necessary, all respondents except 4 of them (98.2\%) responded that it is necessary 'because it affects my health as I eat it (73.5\%)', indicating that they still had a high level of interest in health. Only $43.9 \%$ of the respondents said that they had heard of companion plants, $89.2 \%$ responded that companion plants were effective in eco-friendly management, and $87.4 \%$ showed the will to participate in gardening using companion plants in the future. Finally, the regression analysis confirmed that the awareness of companion plants and satisfaction with gardening activities are key variables that increase the intention to participate in gardening activities in the future.

Conclusion: Since plants require special care depending on the period and various diseases and insect pests occur, there must be continuous research on companion plants as an eco-friendly farming method. Moreover, by actively using companion plants in urban gardens with the utility value in not only eco-friendly pest control but also in helping plant growth, urban agriculture is expected to be continuously activated and promoted by increasing satisfaction in gardening activities with aesthetic landscaping and pest control.

Keywords: diversity, organic agriculture, pest control, sustainability, urban garden

\footnotetext{
This research was supported by the Rural Development Administration's project (PJ01507602).

Received: November 13, 2020, Revised: December 20, 2020, Accepted: January 17, 2021

First author: In Kyoung Hong, inkyoung63@korea.kr, (D) https://orcid.org/0000-0002-7050-5413

*Corresponding author: Hyung Kwon Yun, yun0309@korea.kr, (10) https://orcid.org/0000-0001-9973-4706
} 


\section{Introduction}

As the consumption pattern is changing with more emphasis on health worldwide, the need for safety of agricultural products and sustainable agriculture has emerged, which is rapidly increasing the demand for eco-friendly agriculture (Forschungsinstitut für Biologischen Landbau (FiBL) and International Federation of Organic Agriculture Movements(IFOAM), 2014). Moreover, as urban residents are participating more and more in urban gardening, there is a need for more functional and aesthetic forms of gardens, and there is a growing interest in planting methods that can increase use of small spaces, diversification and use of crops, production of safe foods, and eco-friendly disease and insect pest control that requires little effort (Chae et al., 2019b). As such, since the 1990s when discussions about urban agriculture first began, there has been emphasis on the public value of agriculture, urban-rural exchange, and national interest in agriculture and rural areas (Jang et al., 2012). Making publicized since 2010, there is a constant increase in the interest and demand for urban agriculture among the media, citizens, and organizations (Lee, 2013). Urban agriculture is the act of cultivating or growing crops using lands, buildings, or various living spaces in urban areas. For a long time, companion cropping (mixed cropping) or crop rotation (shift of crops) has been used to reduce damage from diseases and insect pests (Kim et al., 2013). Recently, with the gradual expansion of eco-friendly farming methods, interest in companion planting is growing once again (Ryu and Lee, 2002), and in addition to the urban farming effect, cultivation using companion plants is expanding (Shin et al., 2014).

Companion planting is one of the cropping customs that have been carried out from the past, and by planting different crops together, they help each other, or one helps the other based on the theory that a certain plant can improve or inhibit another plant's growth (Hong et al., 2020). These companion plants are known to be effective in attracting beneficial insects, absorbing nutrients, controlling pests, or providing shades or support, but the term is still unfamiliar to urban residents in Korea. However, in Africa where food is more important than anything else, organic farming is emerging as alternative agriculture to practice the "Green
Revolution in Africa" due to the financial difficulty that keeps farmers from purchasing expensive chemical fertilizers and agricultural pesticide, and thus companion plants are considered suitable for prevention of pests (Hassanali et al., 2008) and are continuously studied in many countries including the U.S. Studies in Korea on eco-friendly pest and weed control using companion plants since 2000 discovered that a greenhouse chrysanthemum farm used Solanum melongena as a trap plant and effectively attracted thrips (Kang et al., 2011). In organic aquaculture of leaf vegetables, Ocimum basilicum, Coriandrum sativum, Houttuynia cordata, Tanacetum cinerariifolium, and Mentha piperita avoided pests (Seo and Kim, 2009), and as a result of using 7 types of Brassicaceae crops such as mustard plants and leaf mustards to attract striped flea beetles, it was found that mustard plants showed the greatest attraction effect (Kim et al., 2013). As such, studies on companion plants as crops promoting plantation diversity and plant growth were mostly focused on controlling diseases and insect pests, while there are relatively insufficient studies on application to and management of urban gardens (Han et al., 2015). Therefore, this study was conducted to understand companion plants and determine the trends of use for active use of companion plants to create aesthetic landscapes with companion plants in actual urban gardens and increase satisfaction in gardening activities such as pest control, thereby providing basic data for sustainable urban agriculture.

\section{Research Methods}

\section{Subjects and methods}

For promotion of garden diversity and use of sustainable urban gardens, this study conducted a survey for 50 days from June 1 to July 20, 2020 on 230 urban residents participating in the Urban Agriculture Expert course in the agricultural technology centers of the Jeolla region (Gwangju, Naju, Wanju, Jeonju), the Chungcheong region (Cheonan), and part of the Seoul region (Yangcheon-gu) to determine the trend of gardening activities, eco-friendly pest control, and use of companion plants. 


\section{Contents}

The survey was comprised of total 24 items: 4 items on demographic characteristics, 9 items on the basics of gardening, 4 items on creation and management of eco-friendly gardens, 6 items on understanding and use of companion plants, and freely writing about crops that the respondents want to grow (Table 1). Despite having to be contactless due to COVID-19, we described in detail the purpose and contents of the survey as well as terminology on companion plants, after which the survey was conducted in self-administered method in which the respondents in each group respond to the questionnaire after answering the questions to perceive the intent of the survey.

\section{Data analysis}

Out of total 230 copies of the questionnaire, 223 copies were ultimately used in the analysis except 7 copies that did not respond to all items or have many missing values. The collected data were analyzed using IBM SPSS statistics Ver. 25 after being counted and organized on Excel. Frequency analysis was conducted on demographic characteristics of the respondents, general matters of gardening activities, eco-friendly garden management, and creation of gardens using companion plants. Satisfaction with gardening activities and intention to participate were rated on a 5-point Likert scale. The respondents were to rate the items on a scale of 1 to 5 , with higher scores indicating higher satisfaction and intention to participate. Regression analysis was conducted to determine the effects of two variables, companion plant terminology recognition and gardening activities, for intention to participate in gardening activities.

\section{Results and Discussion}

\section{Demographic characteristics of respondents}

The characteristics of respondents are as shown in Table

2. There were 64 male $(28.7 \%)$ and 159 female $(71.3 \%)$

Table 2. The respondent's demographic characteristics

\begin{tabular}{|c|c|}
\hline Item & $\mathrm{n}(\%)$ \\
\hline \multicolumn{2}{|l|}{ Gender } \\
\hline Male & $64(28.7)$ \\
\hline Female & $159(71.3)$ \\
\hline Total & $223(100.0)$ \\
\hline \multicolumn{2}{|l|}{ Age } \\
\hline $20 \mathrm{~s}(21 \sim 30)$ & $14(6.3)$ \\
\hline $30 \mathrm{~s}(31 \sim 40)$ & $24(10.8)$ \\
\hline $40 \mathrm{~s}(41 \sim 50)$ & $51(22.9)$ \\
\hline $50 \mathrm{~s}(51 \sim 60)$ & $65(29.1)$ \\
\hline $60 \mathrm{~s}(61 \sim 70)$ & $63(28.2)$ \\
\hline Over 70 s & $6(2.7)$ \\
\hline Total & $223(100.0)$ \\
\hline \multicolumn{2}{|l|}{ Occupation } \\
\hline Homemakers & $59(26.5)$ \\
\hline Self-employed & $42(18.8)$ \\
\hline Specialized professions & $32(14.4)$ \\
\hline Students & $10(4.5)$ \\
\hline Salaried employees & $38(17.0)$ \\
\hline Agriculture-related & $19(8.5)$ \\
\hline Others & $23(10.3)$ \\
\hline Total & $223(100.0)$ \\
\hline \multicolumn{2}{|l|}{ Family members } \\
\hline One member & $29(13.0)$ \\
\hline Two members & $62(27.8)$ \\
\hline Three members & $60(26.9)$ \\
\hline Four members & $49(22.0)$ \\
\hline More than five members & $23(10.3)$ \\
\hline Total & $223(100.0)$ \\
\hline
\end{tabular}

Table 1. Organization of survey items

\begin{tabular}{clcc}
\hline Survey No. & \multicolumn{1}{c}{ Contents } & No. of Item & Reference \\
\hline DV1 $\sim$ DV4 & The respondent's demographic characteristics & 4 & - \\
V1 $\sim$ V9 & Basic gardening & 9 & Youn(2018), Part et al., (2016) \\
V10 $\sim$ V13 & Creation and management of eco-friendly gardens & 4 & RDA(2004), Kim et al., (2013) \\
V14 $\sim 20$ & Garden cultivation using companion plants & 7 & Part et al.(2016), Chae et al., (2019a) \\
\hline
\end{tabular}


respondents, and none of them were under age 20 , while many of them were in their $50 \mathrm{~s}(65,29.1 \%)$ and $60 \mathrm{~s}(63$, $28.2 \%)$, followed by $40 \mathrm{~s}(51,22.9 \%), 30 \mathrm{~s}$ (24, 10.8\%), and $20 \mathrm{~s}(14,6.3 \%)$, and the fewest were $70 \mathrm{~s}$ or older $(6$, $2.7 \%)$. Most of them were homemakers $(26.5 \%)$, followed by the self-employed $(18.8 \%)>$ salaried employees $(17.0 \%)$ $>$ specialized professions $(14.4 \%)>$ others $(10.3 \%)>$ agriculture-related $(8.5 \%)>$ students $(4.5 \%)$. Others were those without jobs after retirement. Most of the respondents had 2 members $(62,27.8 \%)$ and 3 members $(60,26.9 \%)$ in the family, followed by 4 members $(49,22.0 \%), 1$ member $(29,13.0 \%)$, and 5 members or more $(23,10.3 \%)$.

\section{Gardening status}

\section{General matters of gardening}

Regarding gardening experience, 164 respondents (73.5\%) responded that they had experience, while $59(26.5 \%)$ responded that they did not. Most of them $(52,31.7 \%)$ said they participate in gardening no more than once a week, followed by about 2-3 times a week (22.0\%) > almost every day $(21.3 \%)>$ about $4-5$ times a week $(14.6 \%)>$ about once a month $(6.7 \%)>$ about once every other week (3.7\%). This is quite different from the studies by Chae et al. (2019a), Youn (2018), and Park et al. (2016) claiming that most participated 2-3 times a week (32.2\%), which suggests that this frequency is related to accessibility to the garden depending on its location. Most respondents used the crops for self-consumption (91,55.5\%), followed by sharing with family and relatives $(47,28.7 \%)$, sharing with close neighbors $(19,11.6 \%)$, others $(3,1.8 \%)$, and donating to the underprivileged in the community or selling to the market or neighbors (2, 1.2\% each) (Table 3 ), showing similar results with Chae et al. (2019a) and Park et al. (2016).

Most respondents claimed that the biggest difficulty in gardening was pest control methods $(105,64.0 \%)$, followed by management techniques by crop growth stage (43, $26.2 \%)>$ crop cultivation schedule $(8,5.0 \%)>$ others $(4$, $2.4 \%)>$ use of garden crops $(3,1.8 \%)>$ rude behaviors of neighboring gardens (1, 0.6\%) (Fig. 1). Most responded that what they expect from gardening activities is "Growing safe food firsthand" (53, 32.3\%), suggesting that they have continuous interest in health (Fig. 2).
Table 3. The percentage of general items about gardening

\begin{tabular}{lr}
\hline \multicolumn{1}{c}{ Item } & $\mathrm{n}(\%)$ \\
\hline Garden cultivation experience & $164(73.5)$ \\
Yes & $59(26.5)$ \\
No & $223(100.0)$ \\
\hline Total & \\
Garden cultivation times & $52(31.7)$ \\
Not more than once a week & $36(22.0)$ \\
About 2-3 times a week & $24(14.6)$ \\
About 4-5 times a week & $35(21.3)$ \\
Almost everyday & $6(3.7)$ \\
About once every other week & $11(6.7)$ \\
About once a month & $164(100.0)$ \\
Total & \\
\hline Crop utilization method & $91(55.5)$ \\
Self consumption & $47(28.7)$ \\
Sharing with relatives and family members & $19(11.6)$ \\
Sharing with close neighbors & $2(1.2)$ \\
Donating to the underprivileged in the community & $2(1.2)$ \\
Selling to the market or neighbors & $3(1.8)$ \\
Others & $164(100.0)$ \\
\hline Total & \\
\hline
\end{tabular}

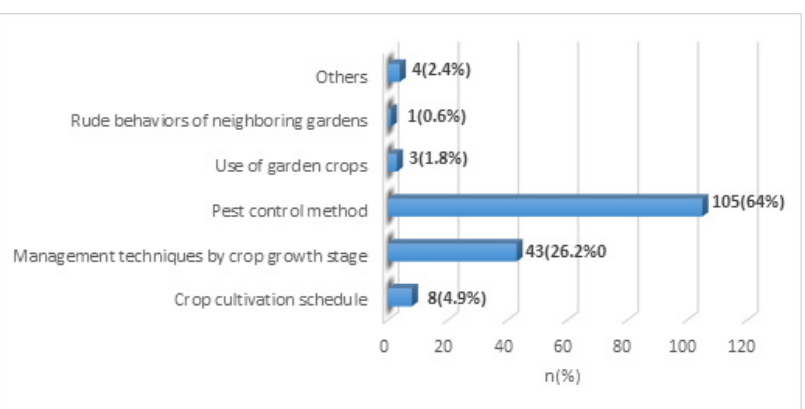

Fig. 1. Biggest difficulty in gardening $(n=164)$.

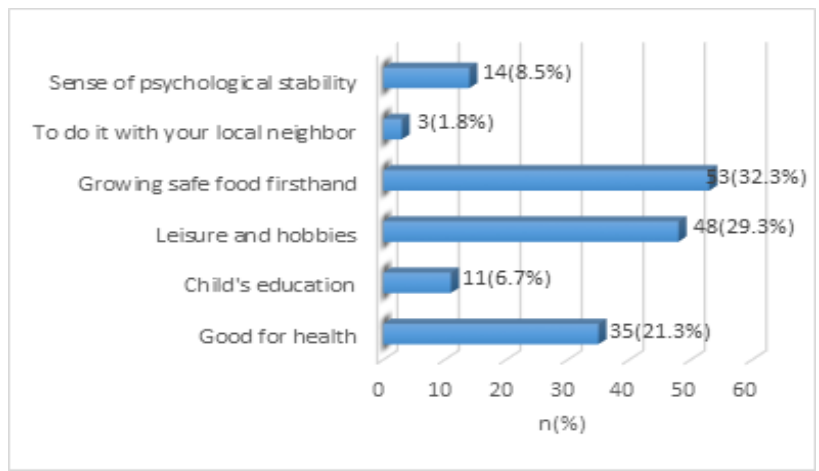

Fig. 2. Expectations from gardening activities $(n=164)$. 


\section{Different perceptions on the purpose of gardening and preferences by gender}

As a result of conducting a survey with multiple dichotomy sets to determine the purpose of gardening and preferred models, it was found that the main purpose of gardening for both men and women was production of safe food ( $\mathrm{M}=8.8 \%, \mathrm{~F}=23.5 \%, \mathrm{~T}=32.3 \%)$. This is consistent with Chae et al. (2019a) and Park et al. (2016), suggesting that there is emphasis on the need for factors related to "health" regarding the gardening purpose of urban residents in the last 5 years, but there was no statistically significant difference (Table 4).

As for preferred garden models, men preferred urban-rural exchange type $(9.6 \%)$ and city park type $(9.3 \%)$, whereas women preferred city park type (30.6\%), showing some difference depending on disposition. Overall, they preferred the city park type garden model (39.9\%), but the garden preference model by gender had a standard deviation of 0 , and thus statistical significance could not be tested (Table 5).

\section{Eco-friendly garden management status}

Regarding how the respondents are preparing nourish- ment for eco-friendly garden management, most responded that they are 'purchasing fertilizers from the market' (134, $60.1 \%$ ), followed by purchasing fertilizers and nutrient supplements sold in the market $(44,19.7 \%)>$ water only $(18$, $8.1 \%)>$ using homemade compost $(17,7.6 \%)>$ getting from others in the neighborhood $(9,4.0 \%)>$ others $(1$, $0.5 \%$ ). To prevent diseases and insect pests, most were 'peeling off the diseased leaf or catch with hands' (109, $48.9 \%$ ), followed by purchasing and spraying agricultural pesticides $(56,25.1 \%)$, not doing pest control $(46,20.6 \%)$, and others $(12,5.4 \%)$, showing consistent results with Chae et al. (2019a). To the question of whether eco-friendly pest control is necessary, all except 4 respondents $(219,98.2 \%)$ answered that it is necessary (Fig. 3), mostly 'because it affects my health as I eat it' $(164,73.5 \%)$, followed by 'to protect various living things in nature' $(36,16.1 \%)$, 'to prevent environmental pollution' (21, 9.4\%), and others (2, $1.0 \%$ ), showing consistent results with Chae et al. (2019a). 122 respondents (54.7\%) said they experienced eco-friendly pest control (Fig. 4), and as a result of presenting the same pest control methods in Chae et al. (2019a), most respondents 'made and sprayed egg yolk seed oil'(68, 55.8\%), followed by others $(26,21.3 \%)>$ purchased and sprayed eco-friendly materials sold in the market such as neem oil

Table 4. Main purpose of gardening by gender( ${ }^{*}$ duplicate selection possible)

\begin{tabular}{|c|c|c|c|c|c|c|c|}
\hline & Item & Male & Female & Total & $\mathrm{t}$ & df & $p$ \\
\hline \multirow{7}{*}{$\begin{array}{c}\text { Main } \\
\text { purpose of } \\
\text { gardening }\end{array}$} & Safe food (production type) & $24(8.8)$ & $64(23.5)$ & $88(32.3)$ & \multirow{7}{*}{-1.000} & \multirow{7}{*}{56.000} & \multirow{7}{*}{$.322^{\mathrm{NS}}$} \\
\hline & Hobbies \& leisure activities & $20(7.4)$ & $56(20.6)$ & $76(28.0)$ & & & \\
\hline & Promotion of physical \& mental health & $20(7.4)$ & $38(13.9)$ & $58(21.3)$ & & & \\
\hline & Promotion of exchange and friendship with neighbors & $5(1.9)$ & $12(4.4)$ & $17(6.3)$ & & & \\
\hline & Child education and learning & $4(1.5)$ & $23(8.4)$ & $27(9.9)$ & & & \\
\hline & Others & $2(0.7)$ & $4(1.5)$ & $6(2.2)$ & & & \\
\hline & Total & $75(27.7)$ & 197(72.3) & $272(100.0)$ & & & \\
\hline
\end{tabular}

${ }^{\mathrm{NS}}$ Non-significant.

Table 5. Preference type of gardening by gender( ${ }^{*}$ duplicate selection possible)

\begin{tabular}{ccccc}
\hline & Item & Male & Female & Total \\
\hline & Community activation type & $17(5.8)$ & $53(18.3)$ & $70(24.1)$ \\
Preference type of & Medium (large) scale production type & $10(3.4)$ & $10(3.4)$ & $20(6.8)$ \\
garden model & City park type & $27(9.3)$ & $89(30.6)$ & $116(39.9)$ \\
& Urban-rural exchange type & $28(9.6)$ & $57(19.6)$ & $85(29.2)$ \\
& Total & $82(28.1)$ & $209(71.9)$ & $291(100.0)$ \\
\hline
\end{tabular}




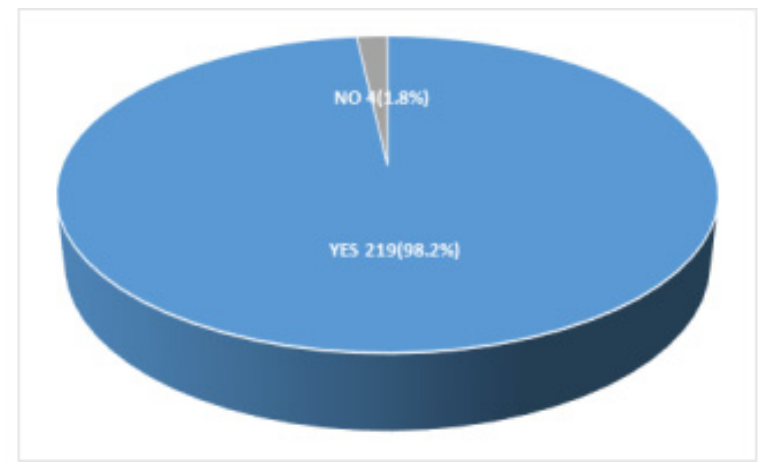

Fig. 3. The percentage of whether eco-friendly control is requires $(n=223)$.

$(17,21.3 \%)>$ made and sprayed plant extracts such as garlic and chili pepper seed $(9,7.4 \%)>$ Made and sprayed extracts from dried Tanacetum cinerariifolium $(2,1.6 \%)$, showing similar results with previous studies. Others included using water from boiled cinnamon bark and ripe Prunus mume made into vinegar, using EM, fermented oil cakes, pyroligneous liquor, egg yolk and vinegar, cooking oil, surfactant, alcohol, used water from washing rice, used coffee grounds, milk + makgeolli, and actually catching the pests (Table 6).

\section{Understanding and using companion plants}

\section{Understanding companion plants}

As a result of the survey on gardens using companion plants (Table 7), only $43.9 \%$ of the respondents said they have heard of companion plants (Fig. 5), which is slightly higher than the survey by Chae et al. (2019b) with $29.9 \%$ but indicating that there is still insufficient awareness of terminology. Among those aware of the term 'companion plant', only $18.8 \%$ had experience creating a garden using companion plants, $42.8 \%$ of which created the garden on an open field (weekend farm). This indicates that various effects must be promoted nationwide to actively change the awareness of companion plants. Regarding the eco-friendly management effect of companion plants, $89.2 \%$ responded that they were effective, $65.4 \%$ of which claimed that 'diseases and pests are reduced'. This is somewhat lower than $75.5 \%$ in the study by Chae et al. (2019a) but still shows that companion plants are effective in controlling diseases and insect pests. $87.4 \%$ of all respondents

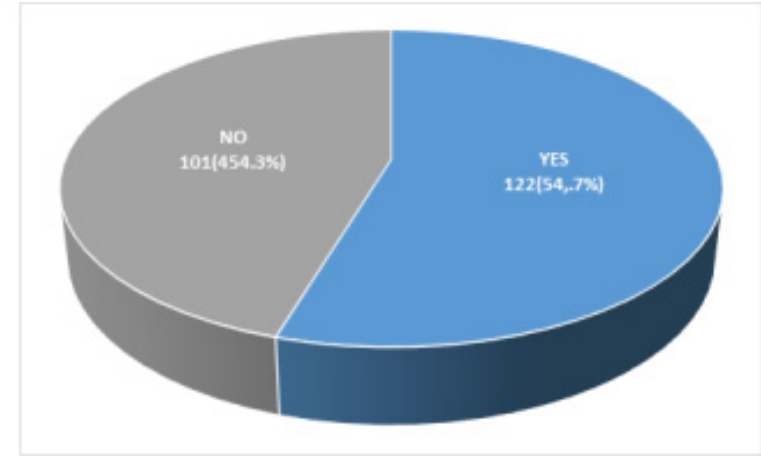

Fig. 4. The percentage of experience in eco-friendly control $(n=223)$.

Table 6. Survey about eco-friendly garden management

\begin{tabular}{lr}
\multicolumn{1}{c}{ Item } & $\mathrm{n}(\%)$ \\
\hline Preparation of fertilizer & $17(7.6)$ \\
Using homemade compost & $134(60.1)$ \\
Purchasing fertilizers from the market & $44(19.7)$ \\
Purchasing fertilizers and nutrient supplements & \\
sold in the market & $9(4.0)$ \\
Getting from others in the neighborhood & $18(8.1)$ \\
Water only & $1(0.5)$ \\
Others & $223(100.0)$ \\
Total & \\
\hline Pest control method & $109(48.9)$ \\
Peeling off the diseased leaf or catch with hands & $56(25.1)$ \\
Purchasing and spraying agricultural pesticides & $46(20.6)$ \\
Not doing pest control & $12(5.4)$ \\
Others & $223(100.0)$ \\
\hline Total &
\end{tabular}

Reasons for eco-friendly control

Affects my health

$164(73.5)$

Protection of various living things existing in nature $\quad 36(16.1)$

Prevention of environmental pollution 21( 9.4)

Others 2( 1.0$)$

Total

$223(100.0)$

Eco-friendly control method

Nanhuangyu (egg yolk seed oil)

$68(55.8)$

Plant extracts such as garlic, chili pepper seeds, etc.

9( 7.4$)$

Tanacetum cinerariifolium

Purchase and spray eco-friendly materials such as

17( 13.9) neem oil

Others

Total

$122(100.0)$ 


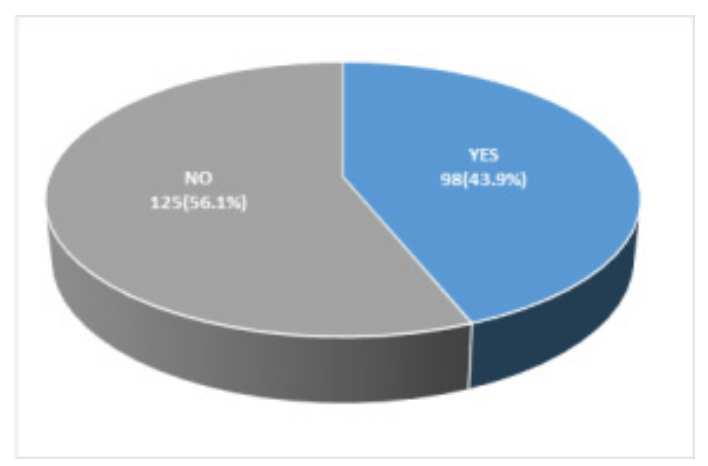

Fig. 5. Recognition of terms for companion plants $(n=223)$.

Table 7. Recognition survey about companion plants

\begin{tabular}{|c|c|}
\hline Item & $\mathrm{n}(\%)$ \\
\hline \multicolumn{2}{|l|}{ Make garden with companion plants } \\
\hline Yes & $42(18.8)$ \\
\hline No & $181(81.2)$ \\
\hline Total & $223(100.0)$ \\
\hline \multicolumn{2}{|l|}{ Garden type to be make } \\
\hline Indoor living space & $6(14.3)$ \\
\hline Exterior space in a house(Artificial ground type) & $6(14.3)$ \\
\hline Container type(Apartment balcony) & $5(11.9)$ \\
\hline A common garden outside an apartment building & $5(11.9)$ \\
\hline Open field (weekend farm) & $18(42.8)$ \\
\hline Mixed type & $2(4.8)$ \\
\hline Total & $42(100.0)$ \\
\hline \multicolumn{2}{|l|}{ Garden managing effect with companion plants } \\
\hline Yes & $199(89.2)$ \\
\hline No & $24(10.8)$ \\
\hline Total & $223(100.0)$ \\
\hline \multicolumn{2}{|l|}{ Effect type of companion plants } \\
\hline Diseases and pests reduced & $130(65.4)$ \\
\hline Plants grow well and grow in quantity & $7(3.5)$ \\
\hline Reduced time spent on gardening & $13(6.5)$ \\
\hline Utilizing methods for the collection of various plants & $44(22.1)$ \\
\hline Others & $5(2.5)$ \\
\hline Total & $199(100.0)$ \\
\hline \multicolumn{2}{|l|}{ Reason not working } \\
\hline Can't experience disease and pest control & $8(33.3)$ \\
\hline $\begin{array}{l}\text { Plants are plentiful, but the number of crops required } \\
\text { is reduced }\end{array}$ & $4(16.7)$ \\
\hline $\begin{array}{l}\text { The growing number of plant types makes it difficult } \\
\text { to manage gardens }\end{array}$ & $1(4.2)$ \\
\hline Difficult to manage as usual & $6(25.0)$ \\
\hline Others & $5(20.8)$ \\
\hline Total & $24(100.0)$ \\
\hline
\end{tabular}

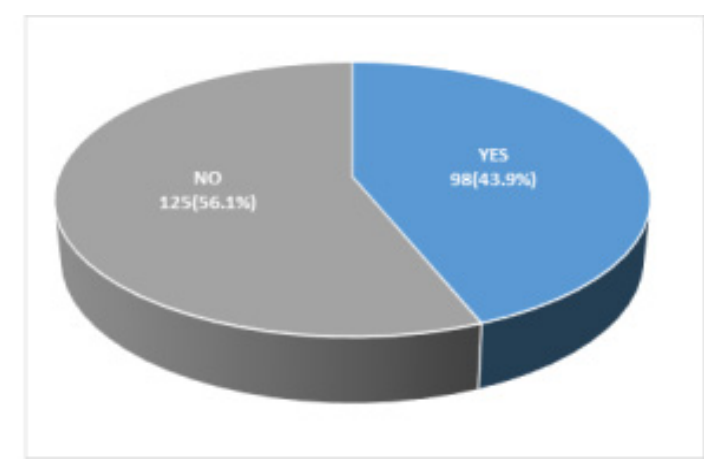

Fig. 6. Participation intention in future $(n=223)$.

Table 8. Correlation between participation in future gardening

\begin{tabular}{cccc}
\hline Item $^{\mathrm{y}}$ & $\mathrm{A}$ & $\mathrm{B}$ & $\mathrm{C}$ \\
\hline $\mathrm{A}$ & 1.000 & & \\
$\mathrm{~B}$ & $-.252^{* * *}$ & 1.000 & \\
$\mathrm{C}$ & $.432^{* * *}$ & $-.119^{\mathrm{NS}}$ & 1.000 \\
\hline
\end{tabular}

Values are mean(standard deviation).

${ }^{\mathrm{y}}$ Item were $\mathrm{A}=$ Participation in future gardening; $\mathrm{B}=$ Perception of companion plants; $\mathrm{C}=$ Satisfaction with gardening

${ }^{\mathrm{NS}}$ Non-significan, ${ }^{* * *}$ at $p<.001$

showed the will to participate in gardens using companion plants in the future (Fig. 6). Thus, more quantitative research must be conducted to determine the effects of various crops.

\section{Intention to participate in gardening activities, companion plant terminology recognition, and satisfaction with gardening activities}

(1) Correlation analysis on intention to participate in gardening activities

As a result of obtaining Pearson's R, which is the correlation coefficient of the intention to participate in gardening activities, there was a correlation between satisfaction with gardening activities and companion plant terminology recognition as shown in Table 8, thereby showing a statistically significant result. However, Kang (2016) claimed that the correlation coefficient below .39 has little relevance, and thus companion plant terminology recognition has a low correlation. 
Table 9. Multiple regression analysis for participation in future gardening

\begin{tabular}{|c|c|c|c|c|c|}
\hline Model & Item & $\mathrm{B}$ & $\beta$ & $\mathrm{t}$ & $p$ \\
\hline \multirow{4}{*}{1} & (Constant) & 3.075 & & 14.765 & $<.001$ \\
\hline & Satisfaction with gardening & .330 & .432 & 6.103 & $<.001$ \\
\hline & $\mathrm{R}^{2}=.187$ Adjusted $\mathrm{R}^{2}=.182, \mathrm{~F}=37.271, p<.001$ & & & & \\
\hline & (Constant) & 3.562 & & 13.542 & $<.001$ \\
\hline \multirow[t]{3}{*}{2} & Satisfaction with gardening & .311 & .408 & 5.852 & $<.001$ \\
\hline & Perception of companion plants & -.280 & -.204 & -2.924 & .004 \\
\hline & $\mathrm{R}^{2}=.228$, Adjusted $\mathrm{R}^{2}=.218, \mathrm{~F}=23.762, p<.001$ & & & & \\
\hline
\end{tabular}

(2) Factors affecting intention to participate in gardening activities

To check the variables affecting intention to participate in gardening activities, which is the dependent variable, we determined the relationship using the unstandardized coefficient (B) and standardized coefficient of multiple regression analysis, after which we conducted a t-test to find out whether the constant and regression coefficient have statistical significance (Table 9). The results showed that satisfaction with gardening activities and companion plant terminology recognition affected intention to participate in gardening activities. The variable that had the greatest effect on intention to participate in gardening activities was satisfaction with gardening activities, followed by companion plant terminology recognition, indicating that people with higher satisfaction with gardening activities had greater intention to participate in gardening activities. This result shows that companion plant terminology recognition and satisfaction with gardening activities are key variables that improve intention to participate in gardening activities.

\section{Crops that the respondents want to grow}

We had 223 respondents freely write down 2 to 10 crops they most want to grow in gardens. As a result of selecting the top 20 crops based on the data, the most preferred crop was Lactuca sativa, followed by Capsicum spp., Zingiber officinale, Capsicum annuum L., Solanum melongena, Solanum lycopersicum, Ocimum basilicum, Allium sativum, Ipomoea batatas, Eruca sativa, Cucumis sativus, Cucumis melo var. makuwa, Daucus carota, Agastache rugosa, Solanum tuberosum, Impatiens balsamina, Allium cepa, Cucurbita moschata, wildflower, and Allium tuberosum.
Cucurbita moschata, wildflower, and Allium tuberosum were preferred by 40 respondents and thus ranked at the bottom side by side within the top 20 . This result is similar to the studies by Lee (2016) and Moon et al. (2014) on types of crops commonly examined, but unlike previous studies, this study showed that there is a growing interest in herbs and flowers aside from vegetables such as herbs, Hydrangea macrophylla, Chrysanthemum, Houttuynia cordata, Geranium, Paeonia lactiflora, Lilium, Tulipa, Tagetes erecta, and edible flowers, thereby providing quite positive results for creation of gardens using companion plants as suggested in this study (Fig. 7). In addition, there were other opinions such as berries, labiatae, and traditional flowers.

As a result of surveying the types of garden crops the respondents want to grow by gender, men most preferred vegetables $(38,17.0 \%)$, followed by medicinal crops $(9,4.0 \%)$, fruit trees and flowers $(6,2.7 \%)$, and herbs $(4,1.8 \%)$, while women most preferred vegetables $(74,33.2 \%)$, followed by herbs $(34,15.2 \%)$, flowers $(27,12.1 \%)$, medicinal crops $(15,6.7 \%)$, and fruit trees $(10,4.5 \%)$. This showed that both men and women most wanted to grow vegetables, which is similar to the study by Chae et al. (2019a). The result of analyzing the significance showed that the significance level of the chi square value 10.274 is 0.036 , which is lower than 0.05 and thus has statistically significant results at the $95 \%$ confidence level. This indicates that there is a difference in preferred crops by gender; men are interested in growing healthy food, while women are interested in not only food but also creating landscape in terms of aesthetics (Table 10). 


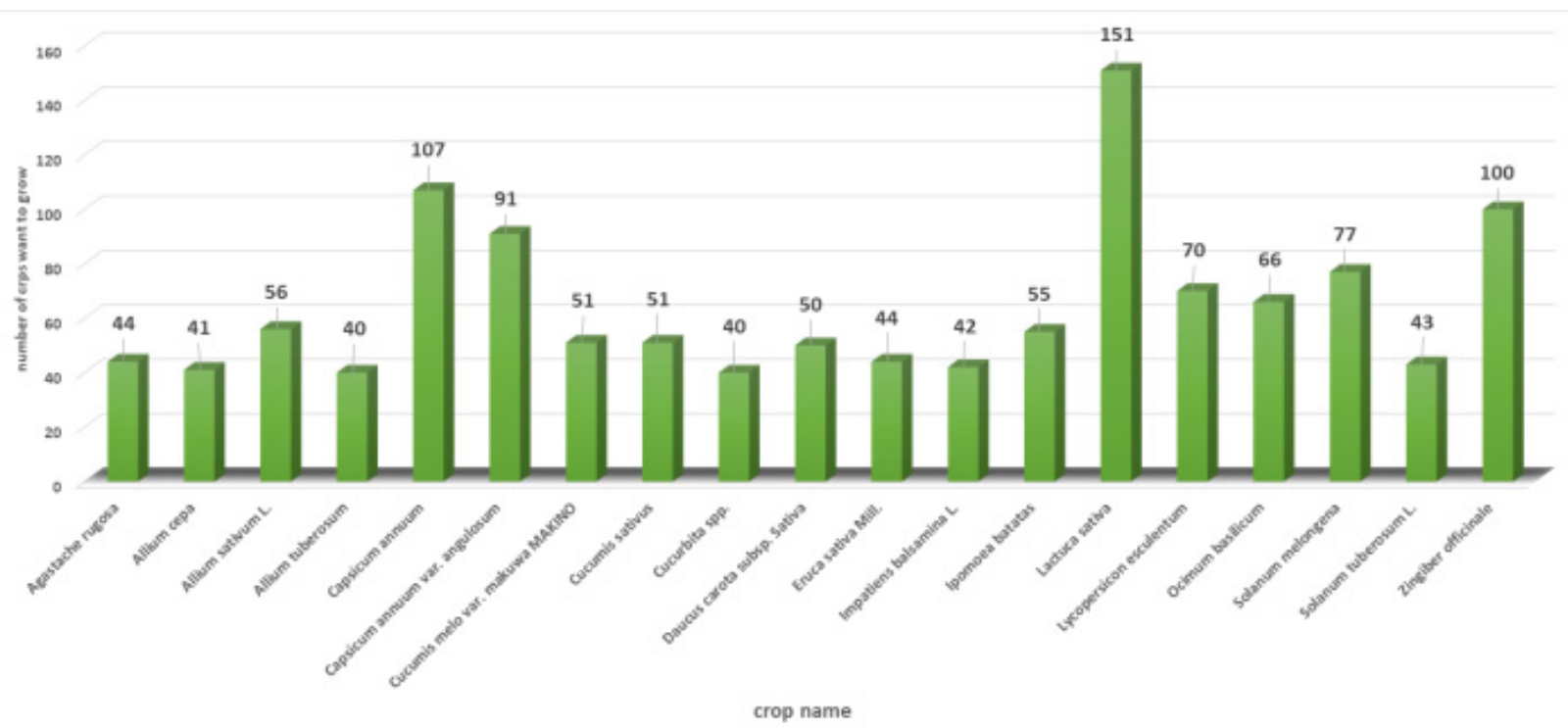

Fig. 7. 20 kinds of crops want to grow( ${ }^{*}$ duplicate selection possible).

Table 10. Type of garden crop preference

unit: $n(\%)$

\begin{tabular}{cccccccc}
\hline & Vegetable & Fruit tree & Medicinal crops & Flower & Herb & Total & \\
\hline Male & $38(17.0)$ & $6(2.7)$ & $9(4.0)$ & $6(2.7)$ & $4(1.8)$ & $63(28.3)$ & $x^{2}=10.274 \mathrm{df}=4$ \\
Female & $74(33.2)$ & $10(4.5)$ & $15(6.7)$ & $27(12.1)$ & $34(15.2)$ & $160(71.7)$ & $p=.036^{*}$ \\
Total & $112(50.2)$ & $16(7.2)$ & $24(10.7)$ & $33(14.8)$ & $38(17.0)$ & $223(100.0)$ & \\
\hline
\end{tabular}

${ }^{*}$ significant at $p<.05$ by t-test.

\section{Conclusion}

As part of research to promote garden diversity and seek sustainable garden management plans, this study was conducted to examine the understanding and use of companion plants as an eco-friendly management plan in urban gardens among urban residents participating in the Urban Agriculture Expert course operated by agricultural technology centers in the Jeolla region, the Chungcheong region, and a part of the Seoul region. The awareness of companion plants among urban residents is as follows.

First, 164 respondents $(73.5 \%)$ answered that they have experience in gardening, most of them once a week (31.7\%) and for self-consumption (55.5\%). Both men and women raised crops to produce safe food (32.3\%), and their most preferred garden type was the city garden type (39.9\%).

Second, to prepare nourishment for eco-friendly garden management, most respondents said they 'purchase fertilizer from the market (60.1\%)'. To prevent diseases and in- sect pests, they claimed that they 'peel off the diseased leaf or catch with hands (48.9\%)'. For the reason why eco-friendly pest control is necessary, all respondents except 4 of them $(219,98.2 \%)$ responded that it is necessary 'because it affects my health as I eat it (73.5\%)', indicating that they still had a high level of interest in health. 54.7\% responded that they had experience in eco-friendly pest control, and most of them 'made and sprayed egg yolk seed oil (55.8\%)' for pest control.

Third, only $43.9 \%$ of the respondents claimed they have heard of companion plants, $18.8 \%$ of which said they have gardened in an open field using companion plants (42.8\%). $89.2 \%$ responded that companion plants are effective in eco-friendly management, and $87.4 \%$ said they intend to participate in gardening using companion plants in the future. Finally, as a result of testing the hypotheses set in this study with multiple regression analysis, it was found that satisfaction with gardening activities and companion plant terminology recognition were variables affecting the 
dependent variable, which is intention to participate in gardening activities.

Fourth, the crops that the respondents want to grow the most were not only vegetables such as Lactuca sativa, Capsicum spp., Zingiber officinale, and Capsicum annuum L., but also herbs and flowers such as Ocimum basilicum, Agastache rugosa, Impatiens balsamina, and wildflowers. Since plants require separate management in each time period and various diseases and insect pests occur, it is necessary to continuously conduct research on companion plants with high utility value that help plant growth in addition to eco-friendly pest control.

This study is an initial research on use of companion plants for eco-friendly operation and management of urban gardens, and its limitation is that the survey could not be conducted on urban residents nationwide due to COVID-19. Nonetheless, the results will have high utility value as the basic data for continuous garden management and aesthetic landscaping as this study determined the trend of actual urban garden users. Based on the contents of this study, further research can seek operation of urban agriculture and improvement of user satisfaction by drawing quantitative data that can guarantee sustainability of urban gardens. This is expected to be actively used in establishing measures for desirable garden management and maintenance plans, thereby continuously activating the use of urban agriculture.

\section{References}

Chae, Y., I.K. Hong, S.M. Lee, Y.B. Jung, K.S, and B.K. Lee. 2019a. A survey on users' perception on the management of eco-friendly urban garden using companion plants. J. People Plants Environ. Vol. 22(Suppl II ):158.

Chae, Y., I.K. Hong, S.M. Lee, Y.B. Jung, K.S. Han, Y.A. Jang, and S.H. Youk. 2019b. Effects of mixed cultivation of companion plant in urban garden on the pest development and growth of cabbages. Hortic. Sci. Technol. Vol. 37(Suppl I ):75-76.

Forschungsinstitut für Biologischen Landbau(FiBL) and International Federation of Organic Agriculture Movements (IFOAM). 2014. The world of organic agriculture: statistics and emerging trends. Frick, Switzerland: Organic eprints.

Han, E.J., J.P. Choi, Y.K. Kim, S.J. Hong, J.H. Park, C.K. Shim, M.J. Kim, and S.C. Kim. 2015. Suppressive effect of repellent plant cultivation against striped flea beetle of chinese cabbage. Korean J. Org. Agric. 23(4):911-921.

Hassnali, A., H. Harren, Z.R. Khan, J.A. Pickett, and C.M. Woodcock. 2008. Intergrated pest management: the push-pull approach for controlling insect pests and weeds of cereals, and its potential for other agricultural systems including animal husbandry. Philos. Trans. R. Soc. Lond. B. Biol. Sci. 363(1491):611-621. https://doi.org/10.1098/rstb.2007.2173

Hong, I.K., H.K. Yun, Y.B. Jung, S.M. Lee, and B.K. Lee. 2020. Classification of crops by type of companion plant. J. People Plants Environ. Vol. 23(Supplement I ):11.

Jang, B.G., Y.J. Choi, and C.C. Cho. 2012. A study on assessment of urban agriculture education program: Focused on urban agriculture instructor course at Gyeonggi Provincial Agricultural Research \& Extension Services. J. Agric. Ext. Community Dev. 19(2):273-299.

Kang, J.H. 2016. Using statistical analysis according to the new spss program. Seoul, Korea:Crownbook Press.

Kang, T.J., Y.S. Choi, I.S. Hwang, H.J. Kim, and G.R. Choi. 2011. Attractant effect of trap plant and natural enemy on biological control of frankneiela occidentalis in PVC chrysanthemum house. Korean. Soc. Appl. Entomol. Suppl. II:157.

Kim, M.J., C.K Shim, Y.K. Kim, H.J. Jee, J.C. Yun, J.H. Park, E.J. Han, and S.J. Hong. 2013. Effect of inter-and mixed cropping with attractant and repellent plants on occurrence of major insect pests in organic cultivation of Chinese cabbage. Korean J. Org. Agric.. 21(4):685-699.

Lee, B.G. 2016. The characteristics of kitchen garden of urban agriculture in Busan. Master's thesis, Kyungsang University, Busan, Korea.

Lee, D.G. 2013. A study of the preference on the type of urban agriculture and activity preferences by lifestyle. Master's thesis, Hanyang University, Seoul, South Korea.

Moon, J.H., S.M. Lee, S.J. Jeong, A.K.Kim, J.J. Choi, K.N. Gim, and D.G. Park. 2014. Preference of crop species of allotment gardeners. Korean J. Hortic. Sci. Technol. Vol. 32(Suppl II ):64.

Park, E.H., E.H. Yoo. K.S. Han. Y.N Jang, S.J. Jeong, 
and D.K. Park. 2016. Utilization analysis on participants of functional vegetabel garden model for urban agriculture. J. Korean Soc. People Plants Environ. 19(5): 393-401, http://dx.doi.org/10.11628/ksppe.2016.19.5.393.

Rural Development Adminstration. 2004. Practice of eco-friendly agricultural methods for horticultural crops. Suwon, Korea: RDA.

Ryu, M.I. and J.H. Lee. 2002. Population ecology. Seoul: Seoul National University Press.

Seo, S.Y, and Y.G. Kim. 2009. Two entomopathogenic bacteria, Xenorhabdus nematophila $\mathrm{K} 1$ and Photorhabdus temperata subsp. temperata ANU101 secrete factors en- hancing $\mathrm{Bt}$ pathogenicity against the diamondback moth, Phutella xylostella. Kor. J. Appl. Entomol. 38: 385-392. https://doi.org/10.5656/KSAE.2009.48.3.385

Shin, Y.S., H.N. Yoo, S.H. Jeong, Y.H. Yun, and J.H. Joo. 2014. Environmentally friendly urban a riculture using public plants in roof greening. Korean Environ. Sci. Soc. Vol.23 (Suppl) 741-743.

Youn, E.S. 2019. A comparative study on the operation status and user's perceptions of urban garden fields. Master's thesis, Daegu Hanny University, Daegu, South Korea. 